\title{
Ebelik Öğrencilerinin Fiziksel Aktivite ve Akademik Başarı Durumlarının İncelenmesi
}

\author{
Yasemin Erkal Aksoy ${ }^{\oplus}$, Şeyma Çatalgöl ${ }^{2} \oplus$, Melek Balçık Çolak ${ }^{3} \oplus$, Yeşim Yeşil ${ }^{4} \oplus$, \\ Hale Karapolat ${ }^{5}$ (1)
}

'Selçuk Üniversitesi Sağlık Bilimleri Fakültesi, Ebelik Bölümü, Konya, Türkiye

2Uşak Üniversitesi Sağlık Yüksekokulu, Hemşirelik Bölümü, Uşak, Türkiye ${ }^{3}$ Ege Üniversitesi Sağlık Bilimleri Fakültesi , Ebelik Anabilim Dalı, İzmir, Türkiye

${ }^{4}$ Mardin Artuklu Üniversitesi Sağlık Bilimleri Fakültesi, Ebelik Bölümü, Mardin, Türkiye

${ }^{5}$ Ege Üniversitesi Tıp Fakültesi, Fizik Tedavi ve Rehabilitasyon Bölümü, İzmir, Türkiye

Yasemin Erkal Aksoy, Öğr. Gör. Dr. Şeyma Çatalgöl, Öğr. Gör. Dr. Melek Balçık Çolak, Uzman Ebe Yeşim Yeşil, Arş. Gör. Hale Karapolat, Doç. Dr.

İletişim:

Öğr. Gör. Dr. Yasemin Erkal Aksoy

Selçuk Üniversitesi Sağlık Bilimleri Fakültesi, Ebelik Bölümü, Konya, Türkiye Tel: +903322233542

E-Posta: ebeyaseminerkal@hotmail.com

\section{ÖZET}

Amaç: Araştırma, Balıkesir, Konya, İzmir olmak üzere üç şehirdeki lisans eğitimine devam eden ebelik bölümü öğrencilerinin yıl sonu başarı puanı ile fiziksel aktivite arasındaki ilişkiyi belirlemek amacıyla tanımlayıcı türde yapıımıştı.

Materyal-Metod: Araştırma evrenini Konya, Balıkesir ve İzmir illerindeki devlet üniversitesi ebelik bölümü birinci sınıfta öğrenim gören 234 öğrenci oluşturmuştur. Araştırmanın verileri literatür taranarak hazırlanan öğrencilerin sosyo-demografik özelliklerini içeren anket formu ile Uluslararası Fiziksel Aktivite Değerlendirme Anketi Kısa Formu kullanılarak toplanmıştır.

Bulgular: Çalışmaya katılan öğrencilerin yaş ortancası $19.0(\min =18.0, \max =28.0)$, beden kütle indeksleri ortancası 20.83 ( $\min =15.78, \max =31.74$ ) olarak saptanmıştır. Ebelik birinci sınıf öğrencilerinin $\% 6.8$ 'inin sigara ve $\% 11.5^{\prime}$ inin alkol kullandığı saptanmıştır. Sigara kullanma durumları ile yaş, vücut ağırığı, boy, başarı puanı, toplam MET (Metabolik Eşdeğer) değeri ve beden kütle indeksi arasında anlamlı bir fark olmadığı saptanmıştır ( $p>0.05)$. Ebelik öğrencilerinin başarı puanları ile düzenli fiziksel aktivite yapma durumları (toplam MET skoru), beden kütle indeksi, vücut ağırlıkları karşıllaştırıldığında aralarında anlamlı bir ilişki olmadığı saptanmıştır ( $p>0.05)$.

Sonuç: Çalışmanın üniversite birinci sınıf öğrencilerinde yapılmış olması nedeniyle bir adaptasyon süreci yaşadıkları ve bu nedenle düzenli fiziksel aktivite yapamadıkları görülmüş̧ür. Çalışmanın daha fazla sayıda, farklı yaş grupları ve farklı sınıflarda tekrarlanması önerilmektedir.

Anahtar sözcükler: Ebelik, fiziksel aktivite, başarı

\section{THE INVESTIGATION OF PHYSICAL ACTIVITY AND ACADEMIC ACHIEVEMENT OF MIDWIFERY STUDENTS}

\section{ABSTRACT}

Objective: The research was carried out in a descriptive type in order to determine the relationship between the yearend achievement score and the physical activity of the midwifery department students who underwent undergraduate education in three cities, Balıkesir, Konya and Izmir.

Materials-Methods: The research/study population included 234 students in the first class of the midwifery department in the provinces where Konya, Balıkesir and Izmir state universities are located. The data of the study were collected by using a questionnaire that includes the socio-demographic characteristics of the students prepared by searching the literature and the International Physical Activity Evaluation Questionnaire Short Form.

Results: The average age of the students participating in the survey was 19.0 ( $\mathrm{min}=18.0$, maximum $=28.0$ ), and median body mass index was 20.83 ( $\min =15.78, \max =31.74$ ). It was determined that $6.8 \%$ of the first-year midwifery students were smoking cigarettes, $11.5 \%$ using alcohol. There was no significant difference between smoking status and age, body weight, height, achievement score, total MET (Metabolic Equivalence) values and body mass index ( $p>0.05$ ). It was determined that there was no significant correlation between the achievement scores of the midwifery students and their exercise status (total MET score), body mass index, body weight ( $p>0.05$ ).

Conclusion: The study was conducted on first-year university students so they were experiencing an adaptation process and thus could not exercise regularly. It is recommended to repeat the study with more participants, different age groups and different classes.

Keywords: Midwifery, physical activity, achievement
Gönderilme Tarihi : 15 0cak 2018

Revizyon Tarihi : 14 Mart 2018

Kabul Tarihi $\quad$ : 21 Mart 2018 
G ünlük yaşamda iskelet kaslarının kasılmasıyla üretilen ve enerji tüketiminde, kalori gereksiniminde önemli bir artışa neden olan herhangi bir bedensel hareket fiziksel aktivite olarak tanımlanır $(1,2,3)$. Herkes yaşamını sürdürmek için fiziksel aktivite gerçekleştirir; ancak fiziksel aktivitenin miktarı çoğunlukla kişisel tercihlere tabidir ve kişiden kişiye önemli ölçüde farklılık gösterebilir. Yürüyüş, bisiklet, merdiven çıkma, ev işleri, rekreasyonel aktiviteler, bahçe işleri, araba yıkama gibi aktiviteler gündelik fiziksel aktivite çeşitleridir (4). Düzenli fiziksel aktivitenin bireyler için fiziksel ve zihinsel sağlık açısından sayısız yararları vardır $(4,5)$. Fiziksel aktivite, her yaşta sağlığa yararlıdır ancak özellikle çocukların, gençlerin sağlıklı büyümesi ve gelişmesinde, istenmeyen kötü alışkanlıkların önlenmesinde ve sosyalleşmede, yetişkinlerin çeşitli kronik hastalıklardan korunmasında veya bu hastalıkların tedavisinde veya tedavinin desteklenmesinde, yaşlıların aktif bir yaşlıık dönemi geçirmelerinin sağlanmasında önemli bir role sahiptir $(6,7)$. Rehberlerin önerilerine göre kanıta dayalı olarak, yetişkin bireyler başlangıçta haftada 3-5 gün, 3045 dakikalık orta şiddette düzenli fiziksel aktiviteye teşvik edilmelidir $(8,9,10)$. Üniversite eğitimi gören gençlerin bilgi ve beceri düzeyleri değerlendirilerek başarı seviyeleri belirlenebilmektedir (11). Eğitimde başarı, genellikle okulda okutulan derslerde geliştirilen ve öğretmenlerce takdir edilen notlarla, test puanlarıla ya da her ikisi ile belirlenen beceriler veya kazanılan bilgilerin ifadesi olan "Akademik Başarı" kastedilmektedir (12). Genç bireylerde takım oyunları ve sporlarının, sosyal bütünleşme ve sosyal yeteneklerin geliştirilmesine yardımcı olduğu bilinmektedir. Son yıllarda genç insanlarla yapılan çalışmalarda fiziksel etkinliklerin kendilik algısı, yaşıt ve anne-baba ilişkileri, akademik başarı üzerinde olumlu etkilerinin olduğu saptanmıştır $(13,14,15,16,17)$. Ayrıca uluslararası yapılan çalışmada öğretmenlerde fiziksel aktivite düzeyi ile akademik başarı arasında ilişki olduğu saptanmıştır (18). Fişne'nin (19) çalışmasına göre fiziksel olarak aktif bireylerin daha yüksek akademik performansa sahip oldukları bulunmuştur. Aktivite düzeylerinin belirlenmesinin oldukça önem kazandığı günümüzde ülkemizde de bu alanda yapılan çalışmaların azlığı dikkati çekmektedir. Bu çalışmanın amacı, ebelik öğrencilerinin fiziksel aktivite düzeylerini belirlemek, ayrıca yılsonu not ortalaması ile fiziksel aktivite arasında bir ilişkinin olup olmadığını araştırmaktır.

\section{Materyal- metod}

Araştırma, Balıkesir, Konya, İzmir olmak üzere üç şehirdeki lisans eğitimine devam eden ebelik bölümü öğrencilerinin yıl sonu not ortalaması ile fiziksel aktivite arasındaki ilişkiyi belirlemek amacıyla tanımlayıcı tipte yapılmıştır. Araştırma evrenini üç ildeki ebelik bölümü birinci sınıfta öğrenim gören 248 öğrenci oluşturmuştur. Araştırmada örneklem seçimine gidilmemiş olup, Ocak-Nisan 2016 tarihleri arasında anket uygulaması sırasında sınıfta bulunan ve araştırmaya katılmayı kabul eden öğrenciler $(n=234)$ araştırmanın örneklemini oluşturmuştur. Araştırmanın verileri literatür taranarak hazırlanan öğrencilerin sosyo-demografik özelliklerini içeren anket formu ile Uluslararası Fiziksel Aktivite Değerlendirme Anketi Kısa Formu kullanılarak toplanmıştır. Araştırmacılar formları öğrencilerin kendilerinin doldurmaları istemiş̧ir. Formların doldurulmasında süre kısıtlamasına gidilmemiştir. Araştırmanın uygulamasına başlamadan önce üç ildeki Ebelik Bölüm Başkanlığı'ndan, Sağlık Bilimleri Fakültesi Dekanlık ve Sağlık Yüksekokulu Müdürlüklerinden yazılı izin ve araştırmaya katılan öğrencilerden sözel izin alınmıştır. Verilerin değerlendirilmesi bilgisayar ortamında Statistical Package for Social Science 20 (SPSS 20) paket programı kullanılarak yapılmıştır. Verilerin istatistiksel analizinde; sürekli değişkenler ortalama ile standart sapma, kategorik değişkenler ise sayı ve yüzde, ilişki ise ki-kare analizi ile sunulmuştur.

\section{Veri toplama araçları}

Sosyo-demografik Anket Formu: Ebelik öğrencilerinin sosyo-demografik özelliklerini içeren (yaş, medeni durum, vücut ağırlığı, boy, sigara kullanımı, vs.) 12 soru yer almaktadır.

Uluslararası Fiziksel Aktivite Değerlendirme Anketi Kısa Formu (IPAQ Short Form - International Physical Activity Questionnaire Short Form): Uluslararası Fiziksel Aktivite Değerlendirme Anketi (IPAQ) 15-65 yaş aralığındaki katılımcıların fiziksel aktivite düzeylerini belirlemek amacıyla geliştirilmiştir (20). IPAQ, uluslararası arenada günlük olarak yapılan fiziksel aktiviteyi bireysel raporlara dayanarak fiziksel aktivite düzeyi hakkında geçerli ve karşılaştırılabilir bilgi elde etmek amacıyla geliştirilmiştir. Çalışmada kulIanılan uluslararası fiziksel aktivite değerlendirme (kısa form) anketinin geçerlik ve güvenirlik çalışması Karaca ve Turnagöl (21) tarafından 2007 yılında yapılmıştır. Ölçeğin kullanılabilmesi için sorumlu yazardan mail yoluyla izin alınmıştır.

IPAQ anketinin puanlanması ve skorlaması: Kısa form (7 soru); yürüme, orta şiddetli ve şiddetli aktivitelerde harcanan zaman ve otururken harcanan zaman hakkında bilgi sağlamaktadır. 
Kısa formun toplam skorunun hesaplanması yürüme, orta şiddetli aktivite ve şiddetli aktivitenin süre (dakikalar) ve frekans (günler) toplamını içermektedir. Aktiviteler için gerekli olan enerji MET (Metabolik Eşdeğer)-dakika skoru ile hesaplanır. Bu aktiviteler için standart MET değerleri oluşturulmuştur. Bunlar;

Yürüme = 3.3 MET,

Orta Şiddetli Fiziksel Aktivite $=4.0 \mathrm{MET}$,

Şiddetli Fiziksel Aktivite $=8.0 \mathrm{MET}$,

Oturma $=1.5$ MET.

Bu değerler kullanılarak günlük ve haftalık fiziksel aktivite seviyesi hesaplanır.

Örneğin; 3 gün 30 dakika yürüyen bir kişinin yürüme MET$\mathrm{dk} /$ hafta skoru:

$3.3 \times 3 \times 30=297$ MET-dk/hafta olarak hesaplanmaktadır.

Yürüme MET-dk/hafta $=3.3 \mathrm{X}$ yürüme dakikası $\mathrm{X}$ yürüme gün sayısı

Orta şiddetli MET-dk/hafta $=4.0 \mathrm{X}$ orta şiddetli aktivite dakikası X orta şiddetli aktivite yapılan gün sayısı

Şiddetli MET-dk/hafta $=8.0 \mathrm{X}$ şiddetli aktivite dakikası X şiddetli aktivite yapılan gün sayısı

Toplam, MET-dk/hafta $=$ (yürüme + orta şiddetli + şiddetli + oturma) MET-dk/hafta

Bu sürekli skorlamanın yanı sıra elde edilen sayısal verilere göre sınıflandırma yapılmaktadır. Buna göre 3 aktivite seviyesi vardır:

1. İnaktif (Kategori 1) : En alt fiziksel aktivite seviyesidir. Kategori 2 ve 3 içine dâhil edilemeyen durumlar inaktif olarak düşünülür.

2. Minimal Aktif (Kategori 2): Aşağıdaki kriterlerden herhangi birine girenler minimal aktiftir.

a. 3 veya daha fazla gün en az 20 dakika şiddetli aktivite yapmak

b. 5 veya daha fazla gün orta şiddetli aktivite veya yürümenin günde en az 30 dakika yapılması

c. Minimum 600 MET-dk/haftayı sağlayan 5 veya daha fazla gün yürüme ve orta şiddetli aktivitenin birleşimi

3. Çok Aktif ( Kategori 3): Bu ölçüm yaklaşık olarak en az günde bir saat veya daha fazla olan orta şiddetli bir aktiviteye eşittir. Bu kategori, sağlıkla ilgili yararların sağlanmasında gereken düzeydir. a. Minimum 1500 MET-dk/haftayı sağlayan en az 3 gün şiddetli aktivite veya

b. Minimum 3000 MET-dk/haftayı sağlayan 7 veya daha fazla gün yürüme, orta şiddetli veya şiddetli aktivitenin kombinasyonu (21).

\section{Bulgular}

Araştırma kapsamına alınan ebelik birinci sınıf öğrencilerinin fiziksel özelliklerine ilişkin değişkenlerinin dağılımı Tablo 1'de görülmektedir.

Tablo 1. Öğrencilerin fiziksel özellikleri

\begin{tabular}{lcc} 
& $\boldsymbol{X}$ & Min-Max \\
\hline Yaş (yıl) & 19.0 & $18.0-28.0$ \\
Boy (cm) & 163.0 & $150.0-181.0$ \\
Vücut Ağırlı̆ı (kg) & 55.0 & $39.0-95.0$ \\
Beden Kütle İndeksi (kg/m²) & 20.83 & $15.78-31.74$
\end{tabular}

Ebelik birinci sınıf öğrencilerinin sigara-alkol kullanma durumları değerlendirildiğinde, \%6.8'inin sigara ve \%11.5'inin alkol kullandığı saptanmıştır (Tablo 2). Sigara kullananların ise günde ortalama 10 adet sigara içtiği ( $\min =4.0, \max =20.0$ ) belirlenmiştir.

Tablo 2. Öğrencilerin sigara alkol kullanma durumları

\begin{tabular}{lccc} 
Sigara Kullanımı & $\boldsymbol{S}$ & $\%$ & Toplam \\
\hline Evet & 16 & 6.8 & 16 \\
Hayır & 218 & 93.2 & 93.2 \\
Alkol Kullanımı & & & \\
\hline Evet & 27 & 11.5 & 27 \\
Hayır & 207 & 88.5 & 88.5
\end{tabular}

Öğrencilerin sigara kullanma durumları ve toplam MET değerleri arasında anlamlı bir ilişkisi olmadığı ( $p>0.05)$, ancak öğrencilerin alkol kullanma durumları ve toplam MET değerleri arasında istatistiksel olarak anlamlı bir ilişki olduğu saptanmıştır $(p<0.05)$ (Tablo 3 ).

Öğrencilerin sigara ve alkol kullanma durumları ile bazı değişkenlerinin karşılaştırılması yapıldığında yaş, vücut ağırlığı, boy, başarı puanı, toplam MET değeri ve beden kütle indeksi (BKI) arasında anlamlı bir fark olmadığı saptanmıştır ( $p>0.05$ ) (Tablo 4).

Ebelik öğrencilerinin düzenli fiziksel aktivite yapma durumları (toplam MET skoru) ile BKI ve başarı puanları karşılaştıııldığında aralarında anlamlı bir ilişki olmadığı saptanmıştır ( $p>0.05$ ) (Tablo 5). 
Tablo 3. Çalışmaya katılan öğrencilerin sigara-alkol kullanma durumları ve toplam MET puanları arasındaki ilişki

\begin{tabular}{|c|c|c|c|c|c|c|c|c|}
\hline \multicolumn{9}{|c|}{ Toplam MET } \\
\hline & & $<600$ & $600-3000$ & $>3000$ & Toplam & $X^{2}$ & $d f$ & $p$ \\
\hline \multirow{3}{*}{$\begin{array}{l}\text { Sigara Kullanma } \\
\text { Durumu }\end{array}$} & Evet & 0 & 9 & 7 & 16 & & & \\
\hline & Hayır & 35 & 129 & 54 & 218 & 4.650 & 2 & 0.098 \\
\hline & Toplam & 35 & 138 & 61 & 234 & & & \\
\hline \multirow{3}{*}{$\begin{array}{l}\text { Alkol Kullanma } \\
\text { Durumu }\end{array}$} & Evet & 0 & 16 & 11 & 27 & & & \\
\hline & Hayır & 35 & 122 & 50 & 207 & 7.086 & 2 & 0.029 \\
\hline & Toplam & 35 & 138 & 61 & 234 & & & \\
\hline
\end{tabular}

Tablo 4. Sigara ve alkol kullanma durumları ve bazı değişkenlerin karşılaştırıması

\begin{tabular}{|c|c|c|c|c|c|c|c|}
\hline & & $\begin{array}{c}\text { Yaş } \\
\text { (Medyan) }\end{array}$ & $\begin{array}{l}\text { Vücut Ağırlığı } \\
\text { (Medyan) }\end{array}$ & $\begin{array}{c}\text { Boy } \\
\text { (Medyan) }\end{array}$ & $\begin{array}{l}\text { Başarı puanı } \\
\text { (Medyan) }\end{array}$ & $\begin{array}{l}\text { Toplam MET } \\
\text { (Medyan) }\end{array}$ & $\begin{array}{c}\text { BMI } \\
\text { (Medyan) }\end{array}$ \\
\hline \multirow{2}{*}{$\begin{array}{l}\text { Sigara Kullanma } \\
\text { Durumları }\end{array}$} & Evet & 19 & 56 & 166.5 & 2.61 & 2283.0 & 20.31 \\
\hline & Hayır & 19 & 55 & 163.0 & 2.76 & 1708.0 & 20.88 \\
\hline$p$ & & 0.985 & 0.853 & 0.472 & 0.186 & 0.074 & 0.776 \\
\hline \multirow{2}{*}{$\begin{array}{l}\text { Alkol Kullanma } \\
\text { Durumları }\end{array}$} & Evet & 19 & 56 & 163.0 & 2.65 & 1902.0 & 20.37 \\
\hline & Hayır & 19 & 55 & 163.0 & 2.75 & 1668.0 & 20.83 \\
\hline$p$ & & 0.405 & 0.683 & 0.666 & 0.336 & 0.053 & 0.603 \\
\hline
\end{tabular}

*Mann-Whitney U Testi

Tablo 5. Beden Kütle İndeksi ve Başarı puanları ile toplam MET puanlarının karşılaştıııması

\begin{tabular}{|c|c|c|c|c|c|c|c|c|}
\hline \multicolumn{9}{|c|}{ Toplam MET } \\
\hline & & $<600$ & $600-3000$ & $>3000$ & Toplam & $X^{2}$ & $d f$ & $p$ \\
\hline \multirow{3}{*}{ Başarı Puanı } & 1.99 ve altı & 0 & 13 & 7 & 20 & \multirow{3}{*}{4.075} & \multirow{3}{*}{2} & \multirow{3}{*}{0.130} \\
\hline & 2 ve üzeri & 35 & 125 & 54 & 214 & & & \\
\hline & Toplam & 35 & 138 & 61 & 234 & & & \\
\hline \multirow{5}{*}{ Beden Kütle İndeksi } & Zayıf $(<18,50)$ & 7 & 27 & 19 & 53 & \multirow{5}{*}{10.679} & \multirow{5}{*}{6} & \multirow{5}{*}{0.099} \\
\hline & Normal $(18,50-24,99)$ & 26 & 103 & 34 & 163 & & & \\
\hline & Fazla Kilolu $(25,00-29,99)$ & 2 & 7 & 5 & 14 & & & \\
\hline & Obez $(\geq 30,00)$ & 0 & 1 & 3 & 4 & & & \\
\hline & Toplam & 35 & 138 & 61 & 234 & & & \\
\hline
\end{tabular}

\section{Tartışma}

Çalışmamızda ebelik öğrencilerinin düzenli fiziksel aktivite yapma durumları ile BKI arasında anlamlı ilişki olmadığı saptanmıştır. Yapılan benzer çalışmalar incelendiğinde; Savcı ve ark. (22) yaptığı çalışmada BKi'ye göre fazla kilolu olan ve olmayan olgular arasında fiziksel aktivite düzeyi açısından anlamlı bir fark olmadığını belirtmiştir. Hallal ve ark. (23) fiziksel inaktivite ile BKI arasında bir ilişki olmadığını belirtmiştir.
Savcı ve ark. (22) yaptığı çalışmada öğrencilerin \%18'inin sigara, \%27'sinin alkol kullandığını ve sigara içenlerin fiziksel aktivite düzeyinin içmeyenlerden daha yüksek olduğunu belirtmiştir. Burton ve Turrell yaptığı çalışmada (24), sigara içenler arasında yüksek fiziksel inaktivite olduğunu açıklamıştır. Efendi (25), yaptığı çalışmada sigara içen kadınların fiziksel aktivite skorunun sigara içmeyenlere göre anlamlı derecede düşük, oturma sürelerinin ise yüksek 
olduğunu belirtmiştir. Çalışmamızın bulguları literatür ile benzerlik göstermektedir $(22,24,25)$.

Ebelik öğrencilerinin düzenli fiziksel aktivite yapma durumları (toplam MET skoru) ile beden kütle indeksi ve başarı puanları karşılaştırılığında aralarında anlamlı bir ilişki olmadığı saptanmıştır ( $p>0.05)$. Çalışmamızın aksine Akandere ve ark.'nın (26) ortaöğretim öğrencilerinin beden eğitimi dersine yönelik tutum ve akademik başarı motivasyonlarının incelenmesi amacı ile yaptıkları çalışma sonucunda, beden eğitimi dersine ilgisi ve tutumu fazla olan öğrencilerin akademik başarı motivasyonlarında artış olduğu belirlemişlerdir. Çalışmamıza katılan öğrencilerin fiziksel aktivite oranının düşük olması ve örneklem sayısının yetersiz olması nedeniyle akademik başarı ve fiziksel aktivite arasında ilişki bulunamamış olabilir.

\section{Sonuç}

Çalışmamıza katılan öğrencilerin yaş ortancasının genç olması ve kullanılan sigara miktarının az olması nedeniyle sigaranın fiziksel aktivite üzerine olumsuz etkisi bulunamamıştır. Çalışmanın üniversite birinci sınıf öğrencilerinde yapılmış olması nedeniyle bir adaptasyon süreci yaşadıkları ve bu nedenle düzenli fiziksel aktivite yapamadıkları görülmüştür. Çalışmanın daha fazla sayıda, farklı yaş grupları ve farklı sınıflarda tekrarlanması önerilmektedir.

\section{Kaynaklar}

1. Vural Ö, Eler S, Güzel NA. Masa başı çalışanlarda fiziksel aktivite düzeyi ve yaşam kalitesi ilişkisi. SPORMETRE 2010;8:69-75. Erişim: http://dergiler.ankara.edu.tr/dergiler/17/1535/16853.pdf

2. Caspersen CJ, Powell KE, Christenson GM. Physical activity, exercise, and physical fitness: definitions and distinctions for health-related research. Public Health Rep 1985;100:126-31. Erişim: https://www. ncbi.nlm.nih.gov/pmc/articles/PMC1424733/

3. Corbin CB, Pangrazi RP, Franks BD. Definitions: Health, Fitness, and Physical Activity. President's Council on Physical Fitness and Sports Research Digest 2000;3:1-9. Erişim: http://purl.access.gpo.gov/GPO/ LPS21074

4. Karaca A, Ergen $E$, Koruç Z. Fiziksel aktivite değerlendirme anketi (FADA) güvenirlik ve geçerlik çalışması. Spor Bilim Derg 2000;11:17-28.

5. WHO Technical Report Series. Report of a WHO Consultation. Obesity: Preventing and managing the global epidemic. Geneva, Switzerland: World Health Organization; 2000. pp.210-13.

6. Baltacı G. Çocuk ve Spor, 1. Baskı. Ankara: Klasmat Matbaacılık; 2008. pp.7-12.

7. Tunay VB. Yetişkinlerde fiziksel aktivite, 1. Baskı. Ankara: Klasmat Matbaacılık; 2008. pp.3-10.

8. Garber CE, Blissmer B, Deschenes MR, Franklin BA, Lamonte MJ, Lee IM, et al. American College of Sports Medicine Position Stand. Quantity and quality of exercise for developing and maintaining cardiorespiratory, musculoskeletal, and neuromotor fitness in apparently healthy adults: guidance for prescribing exercise. Med Sci Sports Exerc 2011;43:1334-59. [CrossRef]

9. Gibbons RJ, Balady GJ, Bricker JT, Chaitman BR, Fletcher GF Froelicher VF, et al. ACC/AHA 2002 guideline update for exercise testing: a report of the American College of Cardiology/American Heart Association Task Force on Practice Guidelines (Committee on Exercise Testing). Circulation 2002;106:1-59.

10. Thompson PD. Health Appraisal and Risk Assessment, In: American College of Sports Medicine, In: Linda SP, editor. ACSM's Guidelines for Exercise Testing and Prescription, 9th ed. China: Lippincott Williams \& Wilkins;2014. pp.1-35. Erişim: http://antoinedl.com/ fichiers/public/ACSM-guidelines-2014.pdf

11. Koç N. Liselerde öğrencilerin akademik başarılarının değerlendirilmesi uygulamalarının etkililiğine ilişkin bir araştırma. Ankara: Ankara Üniversitesi Eğitim (Bilimleri) Fakültesi Yayınları, No: 104; 1981. pp.28-36.

12. Carter V, Good E. Dictionary of Education, 4th ed. New York: Mcgraw Hill Book Company; 1973. pp.110-660.

13. Van de Loo DA, Johnson MD. The young female athlete. Clin Sports Med 1995; 14:687-707.
14. Faigenbaum AD. Strength training for children and adolescents. Clin Sports Med 2000;19:593-619. [CrossRef]

15. Field T, Diego M, Sanders CE. Exercise is positively related to adolescents' relationships and academics. Adolescence 2001;36:105-10.

16. Rasberry CN, Lee SM, Robin L, Laris BA, Russell LA, Coyle KK, Nihiser AJ.The association between school-based physical activity, including physical education, and academic performance: a systematic review of the literature. Prev Med 2011;52:S10-20. [CrossRef]

17. Fox CK, Barr-Anderson D, Neumark-Sztainer D, Wall M. Physical activity and sports team participation: associations with academic outcomes in middle school and high school students. J Sch Health 2010;80:31-7. [CrossRef]

18. Kwak L, Kremers SP, Bergman P, Ruiz JR, Rizzo NS, Sjöström M. Associations between physical activity, fitness, and academic achievement. J Pediatr 2009;155:914-18.e1. [CrossRef]

19. Fişne $M$. Fiziksel aktivitelere katılım düzeyinin, üniversite öğrencilerinin akademik başarıları, iletişim becerileri ve yaşam tatminleri üzerine etkilerinin incelenmesi, Uzmanlık Tezi. Kayseri: Erciyes Üniversitesi; 2009. ss.85-100.

20. Craig CL, Marshall AL, Sjostrom M, Bauman AE, Booth ML, Ainsworth $\mathrm{BE}$, et al. International physical activity questionnaire:12-country reliability and validity. Med Sci Sports Exerc 2003;35:1381-95. [CrossRef]

21. Karaca A, Turnagöl HH. Çalışan bireylerde üç farklı fiziksel aktivite anketinin güvenirliği ve geçerliği. Hacettepe J Sport Sci 2007;18:6884. Erişim: https://toad.halileksi.net/sites/default/files/pdf/fizikselaktivite-aliskanligini-degerlendirme-anketi-faada-toad.pdf

22. Savcı S. Öztürk M, Arıkan H, İnce Di, Tokgözoğlu L. Üniversite öğrencilerinin fiziksel aktivite düzeyleri. Türk Kardiyol Dern Arş 2006;34:166-172.

23. Hallal PC, Victora CG, Wells JC, Lima RC. Physical ınactivity: prevalence and associated variables in Brazilian adults. Med Sci Sports Exerc 2003;35:1894-900. [CrossRef]

24. Burton NW, Turrell G. Occupation, hours worked, and leisure-time physical activity. Prev Med 2000;31:673-81. [CrossRef]

25. Efendi V. Kadınlarda sigaranın fiziksel aktivite, vücut kompozisyonu ve yaşam kalitesi üzerine etkisi, Yüksek Lisans Tezi. İzmir: Dokuz Eylül Üniversitesi; 2012. ss.34-60.

26. Akandere $M$, Özyalvaç NT, Duman S. Ortaöğretim öğrencilerinin beden eğitimi dersine yönelik tutum ile akademik başarı motivasyonlarının incelenmesi (Konya Anadolu Lisesi örneği). Selçuk Üniv Sos Bilim Enst Derg 2010;24:1-10. Erişim: http://dergisosyalbil. selcuk.edu.tr/susbed/article/view/208/192 